\title{
Manifestations and Management of Flea-Borne Rickettsioses
}

This article was published in the following Dove Press journal:

Research and Reports in Tropical Medicine

\author{
Maria A Caravedo Martinez' \\ Alejandro Ramírez-Hernández ${ }^{2}$ \\ Lucas S Blanton' \\ 'Department of Internal Medicine - \\ Division of Infectious Diseases, \\ University of Texas Medical Branch, \\ Galveston, TX, USA; ${ }^{2}$ Department of \\ Pathology, University of Texas Medical \\ Branch, Galveston, TX, USA
}

\begin{abstract}
Murine typhus and flea-borne spotted fever are undifferentiated febrile illnesses caused by Rickettsia typhi and Rickettsia felis, respectively. These organisms are small obligately intracellular bacteria and are transmitted to humans by fleas. Murine typhus is endemic to coastal areas of the tropics and subtropics (especially port cities), where rats are the primary mammalian host and rat fleas (Xenopsylla cheopis) are the vector. In the United States, a cycle of transmission involving opossums and cat fleas (Ctenocephalides felis) are the presumed reservoir and vector, respectively. The incidence and distribution of murine typhus appear to be increasing in endemic areas of the US. Rickettsia felis has also been reported throughout the world and is found within the ubiquitous cat flea. Flea-borne rickettsioses manifest as an undifferentiated febrile illness. Headache, malaise, and myalgia are frequent symptoms that accompany fever. The incidence of rash is variable, so its absence should not dissuade the clinician to consider a rickettsial illness as part of the differential diagnosis. When present, the rash is usually macular or papular. Although not a feature of murine typhus, eschar has been found in $12 \%$ of those with flea-borne spotted fever. Confirmatory laboratory diagnosis is usually obtained by serology; the indirect immunofluorescence assay is the serologic test of choice. Antibodies are seldom present during the first few days of illness. Thus, the diagnosis requires acute- and convalescent-phase specimens to document seroconversion or a four-fold increase in antibody titer. Since laboratory diagnosis is usually retrospective, when a flea-borne rickettsiosis is considered, empiric treatment should be initiated. The treatment of choice for both children and adults is doxycycline, which results in a swift and effective response. The following review is aimed to summarize the key clinical, epidemiological, ecological, diagnostic, and treatment aspects of flea-borne rickettsioses.
\end{abstract}

Keywords: Rickettsia typhi, murine typhus, endemic typhus, flea-borne typhus, Rickettsia felis, flea-borne spotted fever, rickettsiosis

\section{Introduction}

Murine typhus and flea-borne spotted fever are undifferentiated febrile illnesses caused by Rickettsia typhi and Rickettsia felis, respectively. These organisms are small gram-negative obligately intracellular coccobacilli transmitted to humans by fleas. Murine typhus is much more thoroughly characterized, and infection occurs to some degree throughout the world. Thus, the disease is also frequently referred to as endemic typhus. It is most prevalent in coastal areas of the tropics and subtropics (especially port cities), where rats are the primary mammalian host and rat fleas (Xenopsylla cheopis) are the vector. ${ }^{1}$ In the United States, there is an increasing incidence and geographic distribution. ${ }^{2}$ Here, a cycle of transmission involving
Correspondence: Lucas S Blanton

30I University Boulevard, Galveston, TX 77555-0435, USA

Tel +I (409) 747-0236

Fax +I (409) 772-6527

Email Isblanto@utmb.edu
Research and Reports in Tropical Medicine 2021:12 I-14

๑ 2021 Caravedo Martinez et al. This work is published and licensed by Dove Medical Press Limited. The full terms of this license are available at https://www.dovereres. cc) com/terms.php and incorporate the (reative Commons Attribution - Non Commercial (unported, 33.0 ) License (http://(creativecommons.org/licenses/by-nc/3.00). By accessing the work you hereby accept the Terms. Non-commercial uses of the work are permitted without any further permission from Dove Medical Press Limited, provided the work is properly attributed. For permission for commercial use of this work, please see paragraphs 4.2 and 5 of our Terms (https://www.dovepress.com/terms.php). 
opossums and cat fleas (Ctenocephalides felis) are likely the main drivers of human disease, acting as the amplifying host and vector, respectively. ${ }^{1}$ Rickettsia felis has also been reported throughout the world and is found within the ubiquitous cat flea. ${ }^{3}$ As undifferentiated febrile illnesses, these flea-borne rickettsioses often go unrecognized by physicians. ${ }^{4}$ Initiation of proper treatment - doxycycline requires a high index of suspicion, so recognition is paramount. Knowledge of the clinical features and epidemiology of flea-borne rickettsioses is essential for recognizing illness, and thus, important for establishing a confirmatory diagnosis and initiating timely therapy. The intention of this review is to summarize the key clinical, epidemiological, ecological, diagnostic, and treatment aspects of fleaborne rickettsioses.

\section{Microbiology, Pathogenesis, and Immunity}

Flea-borne rickettsiae are small $(\sim 1.3 \times 0.4 \mu \mathrm{m})$ gramnegative coccobacilli. They have evolved through tremendous genome reduction, jettisoning genes encoding for a variety of enzymes necessary for carbohydrate metabolism, nucleotide production, and lipid biosynthesis. Thus, they have a strict obligately intracellular lifestyle and depend on the host cell's cytosol to provide the nutrients to survive. ${ }^{5,6}$ Rickettsiae are divided into several lineages or clades (ie, the spotted fever, typhus, transitional, and ancestral groups). All but the ancestral group include human pathogens. Rickettsia typhi belongs to the typhus group, along with $R$. prowazekii (the agent of louse-borne epidemic typhus). Rickettsia felis is a member of the transitional group, which is a group of rickettsiae that share features of both the spotted fever and typhus groups. ${ }^{7}$ Other rickettsiae detected in fleas (Candidatus Rickettsia senegalensis and $R$. asembonensis) are phylogenetically similar to $R$. felis and are often referred to as R. felis-like organisms. ${ }^{8,9}$

After the inoculation of rickettsiae into the skin, macrophages and dendritic cells target the organism, which then spread through the lymphatics to regional lymph nodes. The rickettsiae escape hematogenously and infect endothelial cells. Systemic endothelial infection and resultant inflammatory damage lead to increased vascular permeability. ${ }^{10}$ A lymphocytic vasculitis can occur within any organ, as described in clinicopathologic reports describing autopsies of fatal murine typhus. ${ }^{11}$ These vasculitic lesions, when within the microcirculation of the skin, form the characteristic macular rash of a rickettsiosis. When severe, vascular damage leads to extravasation of intravascular fluid into interstitial spaces. This results in intravascular volume depletion, hypotension, and organ hypoperfusion. ${ }^{10}$ The end effects of this process can manifest as pulmonary edema and acute respiratory distress syndrome, acute kidney injury (usually due to prerenal azotemia which can progress to acute tubular necrosis), encephalitis, and death.

Following cutaneous inoculation of rickettsiae, the local response by dendritic cells is important in the formation of an immune response. A crucial component of the innate immune response is performed by natural killer cells, which help control rickettsial infection. ${ }^{12}$ Later, cellular responses by CD4 and CD8 T cells, as well as the formation of antibodies, help clear the organism. ${ }^{12,13}$ Following infection, solid long-lasting immunity is believed to occur. Host factors that are associated with severe or fatal rickettsioses include alcohol abuse, older age, and glucose-6-phosphate deficiency. ${ }^{14,15}$ The underlying mechanisms for these observed risk factors are unknown.

\section{Epidemiology and Ecology of Murine Typhus}

Murine typhus occurs worldwide and is most prevalent in tropical and subtropical regions, more frequently in seaports, where the main rodent reservoirs and flea vectors are found. ${ }^{16,17}$ In the US, human cases were commonly reported during the first half of the 20th century, ${ }^{17,18}$ and a reemergence has been evident during the last few decades in some states. ${ }^{2,14,19-22}$ Similarly, cases have also been reported in Mexico, ${ }^{23,24} \mathrm{Brazil}^{25,26} \mathrm{Colombia}^{27,28}$ and Surinam. ${ }^{29}$ A similar pattern of emergence (or reemergence depending on the locality) is evident in countries across Asia, ${ }^{30,31}$ Europe $^{32-34}$ Oceania, ${ }^{35,36}$ and Africa. ${ }^{37}$

Currently, an urban and a suburban transmission cycle are recognized for this disease, involving different vertebrate and invertebrate hosts under particular ecological conditions. The urban transmission cycle was the first described and involves synanthropic rodents and their fleas as reservoirs and vectors, respectively. Commensal rodents of the genus Rattus, mainly $R$. norvegicus (brown rat) and $R$. rattus (black rat), have been implicated as the primary reservoirs. ${ }^{17}$ Rats become infected in 4-7 days, do not manifest any clinical signs, and sustain a subclinical infection for long periods of time (about 3 weeks). ${ }^{17}$ Other 
synanthropic rodent species, such as Mus musculus (house mice) and other Mus species have been found to be infected with $R$. typhi, as implicated by studies in Australia, ${ }^{38}$ China, ${ }^{39}$ and Tunis. ${ }^{40}$ However, compared to rats, their role as reservoir hosts appear minor, as they are common in domiciles in non-endemic areas and are seldom infested with fleas. ${ }^{17}$ Fleas parasitizing rodents act as vectors in the transmission cycle. The pulicid flea, Xenopsylla cheopis (Oriental rat flea) is recognized as the main vectorial species (it is a common ectoparasite of rats from endemic areas), is found to be naturally infected with $R$. typhi, and successfully acquires and transmits the bacterium under experimental conditions. ${ }^{41,42}$ Other flea species that infest commensal rodents could have a vectorial role in specific ecological conditions and in particular locations - Xenopsylla brasiliensis, ${ }^{43,44}$ Nosopsyllus fasciatus, ${ }^{4,46}$ Leptopsylla segnis, ${ }^{39,47,48}$ and Echidnophaga gallinacea ${ }^{47,49,50}$ have been documented with natural and experimental infections.

In the suburban transmission cycle, opossums and their fleas act as reservoirs and vectors, respectively. This cycle has been recorded in the US, specifically in southern suburban areas of California ${ }^{51-53}$ and Texas, ${ }^{20,54-58}$ where murine typhus is endemic. In the southeastern US during the mid 1940s, control campaigns to capture rats and eliminate their associated fleas through the massive use of dichlorodiphenyltrichloroethane (DDT) drastically reduced the number of cases but also changed the ecological conditions for this pathogen. ${ }^{18,20,47,51,59}$ Opossums (Didelphis virginiana) are synanthropic animals, in close relation to human dwellings and activities. They are frequently infested with cat fleas (Ctenocephalides felis). These fleas also parasitize dogs, cats, and humans. ${ }^{60}$ In California and Texas (depending on the location, year, and testing methods), these animals demonstrate a variable prevalence of antibodies reactive to typhus group rickettsieae. $^{55}$ Seroprevalence can reach values over $60 \%$. $^{20,58}$ Furthermore, low numbers of rats (or other synanthropic rodents) have been captured in these areas, and when present, they are without a serological response, which reinforces the pivotal role of opossums in the transmission cycle. ${ }^{51,54,55}$ As recognized by Brigham (1936), opossums are susceptible to $R$. typhi infection without manifesting fever, other clinical signs, or gross pathological lesions. ${ }^{61}$ Nonetheless, the length of time they remain rickettsemic, their ability to transmit to uninfected fleas, and the kinetics of their antibody response are still unknown. Such information would be helpful to better understand their role as reservoirs or amplifying hosts. Rickettsia typhi-infected cat fleas (C. felis) parasitizing opossums have been found in these localities with variable infection rates (Minimum Infection Rates [MIR]) that range from 0.6 to $7.0 \%{ }^{54,55,57}$ Interestingly, this flea species is highly ubiquitous and is commonly found parasitizing companion animals (cats and dogs), as well as humans. ${ }^{60}$ Recent studies have identified $R$. typhiinfected cat fleas collected from pet and feral cats. ${ }^{62,63}$ In spite of evidence of $R$. typhi infection and antibody response in endemic areas, ${ }^{52,58,63-67}$ the epidemiological role of cats is most likely as a bridge host, to act as a vehicle to bring infected fleas within close proximity to humans. ${ }^{51,62}$ Similarly, the role of dogs in the epidemiology and ecology of murine typhus is not clear. As similar to cats, they may act more as carriers of infected cat fleas. Several works have identified seropositive dogs in locations with human cases or in endemic areas, ${ }^{58,68-73}$ and others have detected rickettsial DNA from blood samples. ${ }^{68,74,75}$ Despite this evidence, the role of cats and dogs as true reservoirs or amplifying hosts should be further addressed through experimental infections and acquisition/transmission studies with fleas.

In addition to the aforementioned flea species, $R$. typhi has been associated with other arthropods through molecular detection, isolation, or experimental infections. Nonetheless, their vectorial competence remains unknown, and their role as vectors is controversial due to limited mobility, host range, and anthropophilic behavior. ${ }^{1}$ Studies with ticks have amplified rickettsial DNA in species like Rhipicephalus sanguineus, ${ }^{75}$ and more recently, in the Brazilian Amazon, Amblyomma spp. ticks are presumably involved in what authors proposed a sylvatic cycle of typhus group rickettsiae. ${ }^{25}$ Additionally, lice (Hoplopleura oenomydis, Pediculus humanus, Polyplax spinulosa), mites (Echinolelaps echidninus, Ascoschoengastia indica, Ornithonyssus bacoti) and bedbugs (Cimex lectularius) have also been implicated as potential vectors. ${ }^{1,17}$

The primary route of transmission for $R$. typhi is through the inoculation of infected flea feces on abraded skin. ${ }^{42,76}$ Alternatively, crushed fleas in contact with the $\operatorname{skin}^{76}$ and aerosols produced from dry flea feces or dry flea tissues could be potential sources of exposure. As detailed by Azad (1990), infection in the flea is initiated when the rickettsiae are ingested and enter the epithelial cells of the midgut. Within the cytoplasm of the midgut cells, the rickettsiae replicate by transverse binary fission 
and are released in the gut lumen to be subsequently excreted with the feces. ${ }^{1}$

\section{Ecology of Rickettsia felis and Rickettsia felis-Like Organisms}

Since the discovery of $R$. felis infecting a cat flea colony in California in $1990,{ }^{77}$ it has been increasingly found within a diverse variety of vertebrate and invertebrate species throughout the world. ${ }^{3}$ Its primary recognized invertebrate host and reservoir is C. felis. These fleas are commonly infected with $R$. felis, and the bacterium is capable of transovarial passage to flea progeny. ${ }^{78}$ Molecular evidence of $R$. felis has also been detected in other species of fleas (Ctenocephalides canis, Pulex irritans, Archeopsylla erinacei, Xenopsylla cheopis, Xenopsylla brasiliensis, Leptopsylla segnis, Leptopsylla aethiopica, Echidnophaga gallinacea, Ctenophthalmus congeneroides, Stenoponia sidimi, Rhadinopsylla insolita, Polygenis gwyni, Orchopeas howardi), ticks (Amblyomma humerale, Rhipicephalus sanguineus, Rhipicephalus bursa, Amblyomma maculatum, Carios capensis), lice (Linognathus setosus), mosquitoes (Anopheles sinensis, Anopheles gambiae, Culex pipiens, Aedes albopictus), bed bugs (Cimex hemipterus), and even non hematophagous insects like book lice (Liposcelis bostrychophila). ${ }^{3,79}$ For the latter, it has been proposed to play an endosymbiotic role due to its influence on parthenogenetic reproduction ${ }^{80}$ and mycetome formation within the insect body. ${ }^{81}$ Similarly, $R$. felis has been detected, by different methods, in diverse vertebrate species including cats, racoons, rats, opossums, and dogs. ${ }^{57,82-85} \mathrm{~A}$ recent experimental infection in dogs reported a long period of rickettsemia (up to 100 days) and recorded $R$. felis transmission from infected dogs to uninfected cat fleas, suggesting that this species could be a natural reservoir. ${ }^{84}$ In spite of these findings, currently, there is no definitive consensus about the vertebrate species that acts as a natural reservoir.

In addition, the other flea-borne rickettsial species, $R$. asembonensis and Candidatus R. senegalensis, seemingly follow a wide geographical pattern of distribution, similar to that of R. felis. Rickettsia asembonensis has been detected in different countries across Africa, ${ }^{8,86-88}$ America, ${ }^{79,89-95}$ and Asia. ${ }^{96-100}$ Similarly, there are reports of Candidatus R. senegalensis from Africa, ${ }^{9,88}$ America, ${ }^{55,89,94,101-103}$ and Asia. ${ }^{99,104,105}$ Both species have been associated with a variety of flea species and other arthropods. The broad range of hosts raises questions about the type of biological relationship between these rickettsiae and its host arthropods. Another area of uncertainty is the relationship of these $R$. felis-like rickettsiae with vertebrates. In spite of nucleic acid detection from the blood and tissues of dogs, ${ }^{106}$ monkeys. ${ }^{96}$ and cats, ${ }^{103}$ a natural reservoir is still unknown and requires investigation.

\section{The Curious and Controversial Epidemiology of Flea-Borne Spotted Fever}

Rickettsia felis infection was first reported from a patient in Texas by PCR in 1991. ${ }^{107}$ In the decades following, increasing numbers of case reports implicated $R$. felis (through molecular detection or serologic means) as an etiologic cause of human disease. ${ }^{108}$ In more recent years, there have been increasing reports of circulating $R$. felis DNA from febrile patients in sub-Saharan Africa ${ }^{109-111}$ and Asia. ${ }^{112,113}$ Interestingly, when control subjects have been added to similar investigations, $R$. felis DNA has also been found from non-febrile controls as well as those with fever. ${ }^{114,115}$ Molecular detection of the organism has been reported from skin lesions of patients as well as from swabs taken from the skin of healthy subjects. ${ }^{116,117}$ This brings to question the possible exogenous contamination of skin from rickettsiae-laden flea feces or infected non-hematophagous arthropods (eg, book lice). ${ }^{118}$ In some studies, it is unclear if other potential, and possibly more compelling, diagnoses were ruled out. Indeed, $R$. felis has been detected in the blood and CSF when other causes of disease were evident (ie, scrub typhus, malaria, and cryptococcal meningitis). ${ }^{119}$ The simultaneous detection of $R$. felis DNA from those with Plasmodium parasitemia is also curious and has led some to hypothesize the possible transmission of $R$. felis by mosquitoes. ${ }^{118,120,121}$ It has also been noted that in California, where flea-borne rickettsioses have been proposed to be caused by both $R$. typhi and $R$. felis, cat fleas are ubiquitously infected with $R$. felis at relatively high rates (both in endemic locations and in locations without reported cases), yet $R$. typhi is only detected in cat fleas in areas reporting rickettsial disease. It seems that if truly pathogenic, the ubiquitous presence and frequency of R. felis-infected cat fleas in California would lead to more widespread distribution of flea-borne rickettsiosis. ${ }^{122}$ These aforementioned findings have 
spurred doubt in regard to the true pathogenic nature of R. felis. ${ }^{122-124}$

\section{Clinical Features of Murine Typhus}

Murine typhus is an undifferentiated febrile illness with a vast range of severity. Although most cases are likely mild and go unrecognized under the assumption of a viral illness, disease can lead to prolonged symptoms, hospitalization, admission to the intensive care unit, and death. $^{4,14,125}$ The incubation is 4-15 days, as estimated in those who report a distinct exposure. ${ }^{126}$ The clinical description of murine typhus has been documented in both children and adults from a variety of geographic regions and is well summarized by Tsioutis and colleagues. $^{125}$ Fever is almost universal and is of abrupt onset. $^{127}$ Other manifestations during the early stages of illness include headache (81\%), malaise (67\%), myalgia (52\%), and anorexia (48\%). Less frequent manifestations nausea/vomiting (27\%), diarrhea (19\%), and abdominal pain $(18 \%)$ - can confound the clinical picture by mimicking a primary gastrointestinal illness. ${ }^{125}$ Often considered the sine que non of a rickettsial illness by clinicians, the presence of rash in those with murine typhus is variable, occurring in roughly half of patients. ${ }^{125}$ Rash is usually faint and pink in coloration. It is therefore detected in darkly pigmented individuals less often than those with light skin (81 versus $20 \%$ ). ${ }^{126}$ The rash is usually macular or papular, ${ }^{126}$ and petechiae are occasionally observed. ${ }^{128,129}$ It is usually distributed on the trunk and migrates to the extremities. ${ }^{126}$ The palms, soles, and face are usually spared. ${ }^{129}$ Unlike many of the tick-borne spotted fever group infections (eg, Mediterranean spotted fever and African tick bite fever), an eschar or inoculation lesion is not a cutaneous feature of murine typhus and has only been described in a single case report. ${ }^{130}$

Numerous laboratory abnormalities may be noted in those with murine typhus, but none are specific and may be noted in a variety of other infectious syndromes. Elevated hepatic transaminases, due to hepatocellular injury, are the most frequently observed abnormality and noted in $79 \%$ of patients. These elevations are usually mild, but in $27 \%$ of cases they have been reported to be over 4-times the upper limit of normal. Other abnormalities related to cellular injury include elevations in lactate dehydrogenase in $73 \%$, alkaline phosphatase in $41 \%$, and creatine kinase in $29 \%$ of cases. ${ }^{125}$ Creatine kinase elevations at levels suggestive of rhabdomyolysis can occur. $^{131,132}$ Endothelial injury contributes to hypoalbuminemia and hyponatremia in $60 \%$ and $35 \%$ of patients, respectively. Abnormalities detected on hemogram include thrombocytopenia in $42 \%$, anemia in $38 \%$, leukopenia in $24 \%$, and leukocytosis in $18 \%$ of cases. Elevation in the erythrocyte sedimentation rate is found in $60 \%$ of cases reporting this laboratory value. ${ }^{125}$ Elevated procalcitonin, a biomarker for bacterial infection, has been reported in $71 \%$ when checked. ${ }^{132}$ When lumbar puncture is obtained, the cerebrospinal fluid (CSF) is usually unremarkable, but when abnormal, it resembles that of aseptic meningitis (eg, elevated protein, normal glucose, and mild lymphocytic pleocytosis). ${ }^{133}$

Most patients with murine typhus recover uneventfully, but failure to treat can cause protracted symptoms. Occasionally, severe manifestations occur; a case series from Germany, which included 28 patients, found $18 \%$ had severe manifestations (eg, pneumonitis, acute kidney injury, and central nervous system involvement). ${ }^{134}$ Pulmonary involvement, in the form of dry cough, occurs in $27 \%$ of those with murine typhus, ${ }^{125}$ and infiltrates on chest imaging occurs in $17 \%$ of cases. ${ }^{135}$ Progression to acute respiratory distress syndrome, albeit infrequent, has been reported. ${ }^{135}$ Acute kidney injury is due to prerenal azotemia, but when prolonged, acute tubular necrosis may occur. ${ }^{136}$ Severe neurologic manifestations in hospitalized patients include confusion (8\%), seizures (4\%), stupor $(4 \%)$, and ataxia $(1 \%){ }^{129}$ The case fatality rate of murine typhus is $0.4 \%$ (a figure that holds steady in both the preand post-antibiotic era). ${ }^{14,137}$

\section{Clinical Features of Flea-Borne Spotted Fever}

Disease attributed to Rickettsia felis, often referred to as flea-borne spotted fever, is not as well characterized as it is for other rickettsioses. As discussed above, there are many aspects of this organism and purported disease that need further study. Since the discovery of $R$. felis, cases have been subsequently reported throughout world. The clinical features of flea-borne spotted fever have been systematically reviewed from published case reports by Parola. ${ }^{108}$ Signs and symptoms from these compiled cases include fever (94\%), rash (71\%), neurologic signs (15\%), gastrointestinal symptoms (9\%), and cough (9\%). The rash is usually maculopapular, and unlike murine typhus, eschar has been noted in $12 \%$ of cases. ${ }^{108}$ There are two reported deaths in patients with meningoencephalitis found to have R. felis detected from their CSF, ${ }^{138}$ though the cause of 
illness and death may have been attributable to an alternate diagnosis (eg, tuberculosis).

\section{Differential Diagnosis}

It is important to reiterate that flea-borne rickettsioses are undifferentiated in their presentation as a febrile illness and have a broad differential diagnosis. The differential diagnosis will vary greatly depending on the epidemiology and demographic characteristics of a patient. In general, the differential diagnosis can be as broad as that for fever of unknown origin and include common bacterial infections (eg, urinary tract infections, pneumonia, endocarditis, and meningitis) and less frequently encountered bacterial infections (eg, rat bite fever, leptospirosis, secondary syphilis, and disseminated gonorrhea). Viral diseases, including those causing mononucleosis syndromes (ie, Epstein-Bar virus, cytomegalovirus, and acute HIV) and viral encephalitides should also be considered. ${ }^{139}$ Due to its constellation of flu-like symptoms, murine typhus has even been mistaken for Covid-19. ${ }^{140}$ In the tropics, other considerations include typhoid fever and other vectorborne infections (eg, yellow fever, malaria, dengue, leishmaniasis). Noninfectious etiologies include Kawasaki disease, vasculitides, drug eruptions, immune thrombocytopenic purpura, and thrombotic thrombocytopenic purpura. ${ }^{139}$

\section{Diagnosis}

The initial diagnosis of flea-borne rickettsioses requires a high degree of clinical suspicion based on a compatible clinical syndrome in the setting of the right epidemiologic situation. Even where the disease is endemic, it is often overlooked - in one study, the median time from onset of symptoms to a presumptive diagnosis was 9 days. ${ }^{4}$ When evaluating a patient with an undifferentiated febrile illness, it is important to include rickettsioses in the differential diagnosis. Historical details (eg, exposure to flea vectors, mammalian reservoirs around the home, or travel to endemic areas) may be useful when considering the pretest probability of Rickettsia spp. as the etiologic agent. Unfortunately, less than a quarter of patients recognize being bit by fleas. ${ }^{125} \mathrm{~A}$ detailed physical exam should be performed to look for faint rash, or in the case of fleaborne spotted fever, an eschar. It should be noted, as discussed in the clinical features section above, that these findings are frequently absent. Abnormalities on basic hematological and biochemical laboratory testing (eg, elevated hepatic transaminases and thrombocytopenia) are clues, but they are non-specific and found in a variety of other community acquired and vector-borne infectious diseases.

Serology is the mainstay of laboratory diagnosis for a rickettsial illness. Assays to detect anti-rickettsial antibodies are widely available to clinicians. The indirect immunofluorescence assay (IFA) for the detection of antityphus group antibodies is the gold standard serologic test for the diagnosis of murine typhus, but enzyme-linked immunosorbent assays (ELISA) are also commercially available. The IFA requires a fluorescent microscope and trained microscopist. It is subject to both interobserver and intraobserver variation in endpoint titer interpretation. ${ }^{141}$ ELISA has the advantage of being automated and offering higher throughput, ${ }^{142}$ but it does not offer an endpoint titer when performed as a standard clinical diagnostic test. Older methods, such as the Weil-Felix test, latex agglutination, and compliment fixation methods have been supplanted by the aforementioned methods (ie, IFA and ELISA). The Weil-Felix test, although still used in some developing countries, is neither sensitive nor specific. ${ }^{143}$

Serology is unable to give a species-specific diagnosis, as antibodies formed after infection with $R$. prowazekii (the agent of louse-borne epidemic typhus) will cross react with antigen derived from $R$. typhi and vice versa. Methods using cross-absorption have enabled the differentiation between infection with $R$. prowazekii and $R$. typhi, but the technique is cumbersome and only performed in the research setting. ${ }^{144}$ Antibodies against $R$. felis have been shown to be more cross reactive to spotted fever group antigen than to typhus group antigen. ${ }^{145}$ Thus, assays aimed to diagnose Rocky Mountain spotted fever in the US, or Mediterranean spotted fever in Europe, should be reactive following infection with $R$. felis. During the first days of illness, antirickettsial antibodies are seldom detected. Reactive antibodies have been detected in $15 \%$ and in $50 \%$ within a week of illness in two different studies of murine typhus. ${ }^{129,146}$ The serologic confirmation of diagnosis is therefore retrospective - requiring demonstration of seroconversion or 4-fold increase in antibody titer from acuteand convalescent-phase specimens. Detection of $\operatorname{IgG}$ is preferred over IgM. The IgM isoform exhibits more cross reactivity to non-rickettsial antigen. It is therefore less specific than $\operatorname{IgG}$ and is not detectable much earlier, limiting its utility to improve sensitivity during acute illness. An IgG titer of 1:64 is the usual diagnostic cutoff in the US, but in areas where the disease is highly endemic, 
a demonstrable seroprevalence in the population may exist. Although a higher cutoff titer in some areas may be in order, ${ }^{147}$ the regional seroprevalence to optimize these cutoffs is often unknown. ${ }^{148}$

Molecular methods to detect rickettsiae from the blood have so far been disappointing. Several techniques (ie, conventional PCR, nested PCR, real-time PCR, and isothermal amplification) using a variety of gene targets have been employed, but despite the ability of nucleic acid amplification techniques to detect small quantities of DNA, there are few circulating organisms within the blood. ${ }^{149}$ A systematic analysis of studies performing molecular testing for those with murine typhus reveals a median sensitivity of blood and tissue PCR of $3 \%$ and $6 \%$, respectively. ${ }^{150}$ The DNA of $R$. typhi has also been detected by next generation sequencing from the blood of 2 pregnant women during the workup for undifferentiated febrile illness. ${ }^{151}$ The use of isothermal amplification techniques in resource limited settings offers a cost-effective diagnostic technique for the detection of infectious pathogens. Indeed, development of such assays for the detection of rickettsiae, as recently demonstrated via recombinase polymerase amplification, ${ }^{152}$ offers a technique that rivals the analytic sensitivity of polymerase chain reaction. Interestingly, purported infection with $R$. felis has been accomplished through PCR amplification and sequencing. The seemly frequent molecular detection of $R$. felis DNA within the blood of subjects is a departure from the paradigm known for other well-characterized rickettsioses.

The immunohistochemical detection of rickettsiae from skin biopsy specimens is an effective means to diagnose a rickettsial disease during early illness. ${ }^{130}$ For murine typhus, the technique uses antibodies against typhus group antigen. ${ }^{11}$ For Rocky Mountain spotted fever, the sensitivity of immunohistochemistry (IHC) is $70 \%$, and the specificity is $100 \% .{ }^{153}$ The sensitivity and specificity of this technique for murine typhus are unknown. Use of IHC has not been utilized for those with reported fleaborne spotted fever. Utilization of IHC as a diagnostic modality is out of reach for most clinicians, as only a few specialized laboratories perform the technique.

Cultivation of rickettsiae is rarely undertaken and not readily available. Culture isolation requires the use of cell culture techniques using antibiotic-free medium, embryonated eggs, or infection and subsequent passage into susceptible animals (eg, guinea pigs). These techniques require technical expertise, and because of the potential for aerosolization during culture and propagation, biosafety level 3 laboratory conditions are required. ${ }^{149}$ Thus, human isolates of $R$. typhi are scarce. ${ }^{154}$ To our knowledge, $R$. felis has never been cultivated from a human.

\section{Treatment}

Treatment of flea-borne rickettsioses leads to a quick and complete recovery. Although the case fatality of murine typhus is relatively low, failure to treat can lead to prolonged illness. Recognition of flea-borne rickettsiosis as a possible cause for undifferentiated febrile illness is key to the timely initiation of empiric treatment. Treatment should not await the results of diagnostic testing. As discussed above, antibodies are usually not present in early illness, and when sent to reference laboratories, there is a lag in obtaining timely results. Prompt empiric therapy with an effective drug can decrease the length of hospitalization. ${ }^{155}$ Failure to recognize and treat can lead to excessive physician visits, hospitalizations, and diagnostic workup. ${ }^{4}$

The choice antibiotics for all rickettsioses are those in the tetracycline class, with doxycycline being is the preferred agent. Tetracyclines exhibit a minimum inhibitory concentration (MIC) to typhus group organisms at concentrations of $0.06-0.25 \mu \mathrm{g} / \mathrm{mL}^{156}$ Doxycycline's MIC against $R$. felis is $0.06-0.125 \mu \mathrm{g} / \mathrm{mL} .{ }^{157}$ The effectiveness of these agents have been demonstrated by vast clinical experience over the course of many years after their introduction. ${ }^{158}$ Recently, a randomized controlled trial comparing doxycycline and azithromycin for murine typhus further demonstrated its effectiveness - the median time to defervesce while on doxycycline was 36 hours. ${ }^{159}$ Doxycycline is the preferred agent for the treatment of flea-borne rickettsioses. It's twice daily dosing schedule makes it more convenient than the more frequent dosing of older tetracyclines. Absorption of doxycycline, unlike older tetracyclines, is not hindered by the presence of food (the presence of food prevents or minimizes gastrointestinal upset following ingestion of these agents). Doxycycline is given to adults at $100 \mathrm{mg}$, oral or intravenous, twice daily. Doxycycline has excellent oral bioavailability, but when critical illness or severe nausea and vomiting preclude oral use, parenteral therapy should be initiated. ${ }^{160}$ When illness is severe, a one-time $200 \mathrm{mg}$ loading dose should be administered, followed by normal $100 \mathrm{mg}$ twice daily dosing. Parenteral doxycycline is not available in some developing nations. ${ }^{161}$ This can prove to be problematic when treating critically ill patients. True 
allergy to doxycycline is rare, but when present, desensitization protocols are available. ${ }^{162,163}$ Minocycline appears to be just as effective for rickettsioses. It has been used for Japanese spotted fever, a potentially serious illness. ${ }^{164}$ It was used successfully for murine typhus when the price of doxycycline skyrocketed after a national shortage. ${ }^{20}$ Although the older prototype tetracyclines (eg, tetracycline hydrochloride) are effective, the 4 times daily dosing and need to take on an empty stomach, thus intensifying the gastrointestinal side effects, make them undesirable. ${ }^{160}$

Other antibiotics have been used as alternative agents in those with murine typhus and other rickettsioses. Chloramphenicol is recognized as an alternative. Its use is well documented in numerous reports documenting the course of murine typhus. ${ }^{158}$ Chloramphenicol exhibits an MIC of $1-2 \mu \mathrm{g} / \mathrm{mL}$ against typhus group organisms. ${ }^{156}$ Similarly, thiamphenicol (a chloramphenicol-like compound) has an MIC of $1-2 \mu \mathrm{g} / \mathrm{mL}$ against $R$. felis. ${ }^{157}$ Although its success is documented, in a retrospective analysis the time to defervesce while on chloramphenicol was 4.0 days compared to 2.9 days in those who took doxycycline. ${ }^{165}$ In Rocky mountain spotted fever there is a higher case fatality rate in those treated with chloramphenicol compared to those who had been treated with a drug in the tetracycline class $(7.6 \%$ versus $1.5 \%) .{ }^{166}$ Although R. rickettsii, the agent that causes Rocky Mountain spotted fever, is much more pathogenic than those causing flea-borne spotted fever, the higher case fatality in those treated with chloramphenicol is important to consider. Although the drug remains available throughout much of the world, oral chloramphenicol is no longer available in the US, and the intravenous form is difficult to obtain. The usual dose for adults is $500 \mathrm{mg}$, oral or intravenous, every 6 hours. A serious but rare side effect is aplastic anemia.

Fluoroquinolones have been used as alternative agents to treat murine typhus. Ciprofloxacin, ofloxacin, and pefloxacin have undergone in vitro testing to reveal MICs of $0.5-1 \mu \mathrm{g} /$ $\mathrm{mL}$ to typhus group species. ${ }^{156}$ The MIC of ofloxacin and levofloxacin to $R$. felis is also $0.5-1 \mu \mathrm{g} / \mathrm{mL}$. ${ }^{157}$ In those with murine typhus, fluoroquinolones do not appear to be as effective as doxycycline. The mean time to defervesce on ciprofloxacin is 4.2 days compared to the 2.9 days for those on doxycycline. ${ }^{165}$ In Mediterranean spotted fever (a spotted fever group rickettsiosis cause by $R$. conorii), cases of severe illness have been associated with the use of fluoroquinolones, possibly due to the overexpression of a toxin-antitoxin system. ${ }^{167,168}$ This tempers the enthusiasm of fluoroquinolones as an alternative agent.
The macrolide azithromycin is an attractive choice as an alternative agent, as it has an MIC of $0.1 \mu \mathrm{g} / \mathrm{mL}$ to R. typhi. ${ }^{169}$ Case reports describing its use in those with typhus group rickettsioses have been mixed. Unfortunately, in a randomized controlled trial, azithromycin was not effective when compared to doxycycline. Azithromycin was associated with a longer median time to defervesce (48 hours) than doxycycline, and it was associated with more treatment failures $(4.2 \%$ versus $1.4 \%[\mathrm{P}<0.001]) .{ }^{159}$

Many antibiotics commonly used as empiric treatment in the outpatient and inpatient settings, such as beta lactams, have no activity against flea-borne rickettsiae. Sulfonamides, such as trimethoprim-sulfamethoxazole, also have no activity. ${ }^{156,157}$ As recognized with other rickettsioses, their use has been associated with progression to severe disease. ${ }^{170}$

\section{Treatment in Special Populations}

The preferred treatment in pregnant patients with a fleaborne rickettsiosis is doxycycline. Older tetracyclines have been implicated as having teratogenic effects on the bones and developing teeth of the fetus. ${ }^{171,172}$ They are also associated with the development of maternal pancreatitis and hepatotoxicity. ${ }^{173}$ Although these adverse effects carry over as warnings for newer tetracyclines, there is little evidence that such adverse events occur in pregnant women given doxycycline. ${ }^{174}$ Although there have been case reports of the successful use of azithromycin for pregnant women with murine typhus, the results of the aforementioned clinical trial, comparing azithromycin to doxycycline, are not encouraging for the efficacy of azithromycin. ${ }^{159}$ Considering the lack of evidence implicating doxycycline in severe adverse events during pregnancy, the benefits of its use likely outweigh the risks. ${ }^{175}$

The treatment of choice for children remains doxycycline - its use is endorsed by the Pediatric Red Book. ${ }^{176}$ Doxycycline $2.2 \mathrm{mg} / \mathrm{kg}$ by mouth twice daily is the recommended dose. It should be given for 7 days. As with adults, the parenteral formulation is only necessary if nausea and vomiting are worsened by the oral version or severe enough to impede absorption. Although the potential for staining developing permanent teeth causes great hesitancy for physicians to prescribe doxycycline to children, studies have demonstrated that short and infrequent courses of doxycycline cause no appreciable differences in the shade of permanent teeth. ${ }^{177,178}$ Chloramphenicol (as stated above) appears to be an inferior alternative. In areas of the world where chloramphenicol is still available, the 
dosing in children is $12.5 \mathrm{mg} / \mathrm{kg}$ every 6 hours. The rare but serious risk of aplastic anemia associated with chloramphenicol should be strongly considered prior to the use of this agent. ${ }^{160}$ Although fluoroquinolones are not absolutely contraindicated in children, their use in the pediatric population is associated with more musculoskeletal events (eg, tendinopathy, tendon rupture, and arthropathy) when compared to other antibiotics. Considering the relatively poor performance of fluoroquinolones in adults with murine typhus, their use in children over doxycycline should be avoided. Although azithromycin is safe in children, it does not appear to be effective. ${ }^{159}$

\section{Supportive Care}

As previously mentioned, most with flea-borne rickettsioses eventually recover with no sequelae, but in those hospitalized, $6 \%$ are severe enough to need stay in the intensive care unit. ${ }^{125}$ During critical illness, supportive care is no different than that of other severe infectious diseases. Attention must be paid to the careful administration of intravenous fluids, as excessive crystalloid in the setting of endothelial injury can lead to pulmonary edema. The development of acute respiratory distress syndrome may require mechanical ventilation. Acute kidney injury, when severe or prolonged, may require renal replacement therapy. The need for renal replacement is usually temporary, as renal function typically recovers. ${ }^{179}$

\section{Prevention}

The control of murine typhus following campaigns to control rat fleas by applying DDT to rat harborages after World War II is an excellent example of how vector control efforts can control an infectious disease. The decrease in flea infestation rates on rats correlated with a rapid fall in human cases. In 1944, 5,401 cases were reported in the US. Following eradication efforts, this fell to less than 100 cases by $1956 .{ }^{180}$ Currently, there are no systematic integrated pest control methods to curb murine typhus in endemic areas. Interestingly, as demonstrated in one study, the use of DDT did not have a spillover effect on $C$. felis infesting opossums. ${ }^{181}$ Since opossums often live and forage in close proximity to human dwellings, development of methods to control fleas on opossums is an intriguing but unestablished approach. There are no studies to support the use of flea control methods around homes, but it seems reasonable that controlling fleas on domestic animals, since they may act as a bridge host to carry infected fleas in close proximity to owners, may help reduce the transmission of flea-borne rickettsiae to humans. Many topically and orally administered flea-control products are available on the market for dogs and cats. ${ }^{60}$ There is no available vaccine to prevent fleaborne rickettsioses, but it is believed that natural rickettsial infection confers long-lasting immunity.

\section{Summary}

Flea-borne rickettsioses are an often-unrecognized cause of febrile illness. The signs and symptoms mimic a variety of other infections. There is no rapid point of care test for the diagnosis during the acute stage of illness. Therefore, a high index of suspicion is paramount. Knowledge of the epidemiology can help the clinician ascertain important historical clues. When the diagnosis is suspected, prompt empiric therapy with doxycycline should be initiated.

\section{Disclosure}

The authors report no conflicts of interest related to this work.

\section{References}

1. Azad AF. Epidemiology of murine typhus. Annu Rev Entomol. 1990;35:553-569. doi:10.1146/annurev.en.35.010190.003005

2. Murray KO, Evert N, Mayes B, et al. Typhus group rickettsiosis, Texas, USA, 2003-2013. Emerg Infect Dis. 2017;23(4):645-648. doi:10.3201/eid2304.160958

3. Brown LD, Macaluso KR. Rickettsia felis, an emerging flea-borne rickettsiosis. Curr Trop Med Rep. 2016;3:27-39. doi:10.1007/ s40475-016-0070-6

4. Vohra RF, Walker DH, Blanton LS. Analysis of health-care charges in murine typhus: need for improved clinical recognition and diagnostics for acute disease. Am J Trop Med Hyg. 2018;98 (6):1594-1598. doi:10.4269/ajtmh.17-0411

5. McLeod MP, Qin X, Karpathy SE, et al. Complete genome sequence of Rickettsia typhi and comparison with sequences of other rickettsiae. $J$ Bacteriol. 2004;186(17):5842-5855. doi:10.1128/JB.186.17.5842-5855.2004

6. Driscoll TP, Verhoeve VI, Guillotte ML, et al. Wholly Rickettsia! Reconstructed metabolic profile of the quintessential bacterial parasite of eukaryotic cells. mBio. 2017;8(5). doi:10.1128/ mBio.00859-17

7. Gillespie JJ, Beier MS, Rahman MS, et al. Plasmids and rickettsial evolution: insight from Rickettsia felis. PLoS One. 2007;2 (3): 266.

8. Maina AN, Luce-Fedrow A, Omulo S, et al. Isolation and characterization of a novel Rickettsia species (Rickettsia asembonensis sp. nov.) obtained from cat fleas (Ctenocephalides felis). Int J Syst Evol Microbiol. 2016;66(11):4512-4517. doi:10.1099/ ijsem.0.001382

9. Mediannikov O, Aubadie-Ladrix M, Raoult D. Candidatus 'Rickettsia senegalensis' in cat fleas in Senegal. New Microbes New Infect. 2015;3:24-28. doi:10.1016/j.nmni.2014.10.005

10. Sahni A, Fang R, Sahni SK, Walker DH. Pathogenesis of rickettsial diseases: pathogenic and immune mechanisms of an endotheliotropic infection. Annu Rev Pathol. 2019;14:127-152. doi:10.1146/annurev-pathmechdis-012418-012800 
11. Walker DH, Parks FM, Betz TG, Taylor JP, Muehlberger JW. Histopathology and immunohistologic demonstration of the distribution of Rickettsia typhi in fatal murine typhus. Am J Clin Pathol. 1989;91(6):720-724. doi:10.1093/ajcp/91.6.720

12. Walker DH, Ismail N. Emerging and re-emerging rickettsioses: endothelial cell infection and early disease events. Nat Rev Microbiol. 2008;6(5):375-386. doi:10.1038/nrmicro1866

13. Walker DH, Popov VL, Feng HM. Establishment of a novel endothelial target mouse model of a typhus group rickettsiosis: evidence for critical roles for gamma interferon and CD8 T lymphocytes. $L a b$ Invest. 2000;80(9):1361-1372. doi:10.1038/labinvest.3780144

14. Pieracci EG, Evert N, Drexler NA, et al. Fatal flea-borne typhus in Texas: a retrospective case series, 1985-2015. Am J Trop Med Hyg. 2017;96(5):1088-1093. doi:10.4269/ajtmh.16-0465

15. Whelton A, Donadio JV, Elisberg BL. Acute renal failure complicating rickettsial infections in glucose-6-phosphate dehydrogenase-deficient individuals. Ann Intern Med. 1968;69 (2):323-328. doi:10.7326/0003-4819-69-2-323

16. Kuo CC, Wardrop N, Chang CT, Wang HC, Atkinson PM. Significance of major international seaports in the distribution of murine typhus in Taiwan. PLoS Negl Trop Dis. 2017;11(3): e0005430. doi:10.1371/journal.pntd.0005430

17. Traub R, Wisseman CL, Farhang-Azad A. The ecology of murine typhus-a critical review. Trop Dis Bull. 1978;75(4):237-317.

18. Anstead GM. History, rats, fleas, and opossums: the ascendency of flea-borne typhus in the United States, 1910-1944. Trop Med Infect Dis. 2020;5(1).

19. Ruiz K, Valcin R, Keiser P, Blanton LS. Rise in murine typhus in Galveston County, Texas, USA, 2018. Emerg Infect Dis. 2020;26 (5):1044-1046. doi:10.3201/eid2605.191505

20. Blanton LS, Vohra RF, Bouyer DH, Walker DH. Reemergence of murine typhus in Galveston, Texas, USA, 2013. Emerg Infect Dis. 2015;21(3):484-486. doi:10.3201/eid2103.140716

21. Green JS, Singh J, Cheung M, Adler FC, Ashouri N. A cluster of pediatric endemic typhus cases in Orange County, California. Pediatr Infect Dis J. 2011;30(2):163-165. doi:10.1097/ INF.0b013e3181f4cc25

22. Abramowicz KF, Rood MP, Krueger L, Eremeeva ME. Urban focus of Rickettsia typhi and Rickettsia felis in Los Angeles, California. Vector Borne Zoonotic Dis. 2011;11(7):979-984. doi:10.1089/vbz.2010.0117

23. Zavala-Castro JE, Dzul-Rosado KR, Peniche-Lara G, TelloMartin R, Zavala-Velazquez JE. Isolation of Rickettsia typhi from human, Mexico. Emerg Infect Dis. 2014;20(8):1411-1412. doi:10.3201/eid2008.130095

24. Zavala-Castro JE, Zavala-Velazquez JE, Sulu Uicab JE. Murine typhus in child, Yucatan, Mexico. Emerg Infect Dis. 2009;15 (6):972-974. doi:10.3201/eid1506.081367

25. Minervino AHH, Labruna MB, Dias SR, et al. Typhus group rickettsiosis, Brazilian Amazon. Emerg Infect Dis. 2020;26 (9):2294-2296. doi:10.3201/eid2609.201305

26. Silva LJ, Papaiordanou PM. Murine (endemic) typhus in Brazil: case report and review. Rev Inst Med Trop Sao Paulo. 2004;46 (5):283-285. doi:10.1590/S0036-46652004000500010

27. Hidalgo M, Salguero E, de la Ossa A, et al. Murine typhus in Caldas, Colombia. Am J Trop Med Hyg. 2008;78(2):321-322. doi:10.4269/ajtmh.2008.78.321

28. Hidalgo M, Montoya V, Martinez A, et al. Flea-borne rickettsioses in the north of Caldas province, Colombia. Vector Borne Zoonotic Dis. 2013;13(5):289-294. doi:10.1089/vbz.2012.1173

29. van Doorn HR, Lo ANSM, Ottenkamp J, Pajkrt D. Widened coronary arteries in a feverish child. Pediatr Cardiol. 2006;27 (4):515-518. doi:10.1007/s00246-006-1324-1

30. Thompson CN, Blacksell SD, Paris DH, et al. Undifferentiated febrile illness in Kathmandu, Nepal. Am J Trop Med Hyg. 2015;92(4):875-878. doi:10.4269/ajtmh.14-0709
31. Aung AK, Spelman DW, Murray RJ, Graves S. Rickettsial infections in Southeast Asia: implications for local populace and febrile returned travelers. Am J Trop Med Hyg. 2014;91 (3):451-460. doi:10.4269/ajtmh.14-0191

32. Rodriguez-Alonso B, Almeida $\mathrm{H}$, Alonso-Sardon $\mathrm{M}$, et al. Murine typhus. How does it affect us in the 21 st century? The epidemiology of inpatients in Spain (1997-2015). Int J Infect Dis. 2020;96:165-171. doi:10.1016/j.jijid.2020.04.054

33. Grouteau G, Lancelot O, Bertolotti A, et al. Emergence of murine typhus in La Reunion, France, 2012-2017. Med Mal Infect. 2020;50(1):22-27. doi:10.1016/j.medmal.2019.06.003

34. Portillo A, Santibanez S, Garcia-Alvarez L, Palomar AM, Oteo JA. Rickettsioses in Europe. Microbes Infect. 2015;17(11-12):834-838. doi:10.1016/j.micinf.2015.09.009

35. Lim MY, Weinstein P, Bell A, Hambling T, Tompkins DM, Slaney D. Seroprevalence of antibodies to Rickettsia typhi in the Waikato region of New Zealand. Epidemiol Infect. 2016;144 (11):2283-2289. doi:10.1017/S0950268816000698

36. Derne B, Weinstein P, Musso D, Lau C. Distribution of rickettsioses in Oceania: past patterns and implications for the future. Acta Trop. 2015;143:121-133. doi:10.1016/j.actatropica.2014. 10.012

37. Letaief A. Epidemiology of rickettsioses in North Africa. Ann N Y Acad Sci. 2006;1078:34-41. doi:10.1196/annals.1374.004

38. Wheatland F. A fever resembling a mild form of typhus fever. Med J Aust. 1926;1:261-266. doi:10.5694/j.1326-5377.1926. tb39259.x

39. Liu W, Zia SH. Typhus Rickettsia isolated from mice and mouse-fleas during an epidemic in Peiping. Proc Soc Exp Biol Med. 1940;45(3):823-826. doi:10.3181/00379727-45-11849P

40. Sparrow $H$. Enquete sur la presence du virus typhique chez les souris de Tunis. Arch Inst Pasteur De Tunis. 1935;24:435-460.

41. Dyer RE, Rumreich A, Badger LF. Typhus fever: a virus of the typhus type derived from fleas collected from wild rats. Public Health Rep. 1931;46(7):334-338. doi:10.2307/4579944

42. Dyer RE, Ceder ET, Lillie RD, Rumreich A, Badger LF. The experimental transmission of endemic typhus fever in the United States by the rat flea Xenopsylla cheopis.. Public Health Rep. 1931;46(42):2481-2499. doi:10.2307/4580215

43. Heisch RB. Urban Rattus as the main reservoir of murine typhus in Kenya. J Trop Med Hyg. 1969;72(8):195-196.

44. Leulmi H, Socolovschi C, Laudisoit A, et al. Detection of Rickettsia felis, Rickettsia typhi, Bartonella species and Yersinia pestis in fleas (Siphonaptera) from Africa. PLoS Negl Trop Dis. 2014;8(10):e3152. doi:10.1371/journal.pntd.0003152

45. Mooser H, Castaneda MR. The multiplication of the virus of Mexican typhus fever in fleas. J Exp Med. 1932;55(2):307-323. doi:10.1084/jem.55.2.307

46. Kemp HA. Endemic typhus fever: rat flea as a possible vector. $J$ Am Med Assoc. 1931;97(11):775-777. doi:10.1001/ jama.1931.02730110025007

47. Strandtmann RW, Eben DJ. A survey of typhus in rats and rat ectoparasites in Galveston, Texas. Tex Rep Biol Med. 1953;11 (1):144-151.

48. Azad AF, Traub R. Transmission of murine typhus rickettsiae by Leptopsylla segnis (Siphonaptera: leptopsyllidae). J Med Entomol. 1987;24(6):689-693. doi:10.1093/jmedent/24.6.689

49. Bringham GD. Two strains of endemic typhus fever virus isolated from naturally infected chicken fleas (Echidnophaga gallinacea). Public Health Rep. 1941;32(2):1803-1804. doi:10.2307/4583855

50. Alicata JE. Experimental transmission of endemic typhus fever by the sticktight flea, Echidnophaga gallinacea. J Wash Acad Sci. 1942;32(2):57-60.

51. Adams WH, Emmons RW, Brooks JE. The changing ecology of murine (endemic) typhus in Southern California. Am J Trop Med Hyg. 1970;19(2):311-318. doi:10.4269/ajtmh.1970.19.311 
52. Sorvillo FJ, Gondo B, Emmons R, et al. A suburban focus of endemic typhus in Los Angeles County: association with seropositive domestic cats and opossums. Am J Trop Med Hyg. 1993;48 (2):269-273. doi:10.4269/ajtmh.1993.48.269

53. Eremeeva ME, Karpathy SE, Krueger L, et al. Two pathogens and one disease: detection and identification of flea-borne rickettsiae in areas endemic for murine typhus in California. J Med Entomol. 2012;49(6):1485-1494. doi:10.1603/ME11291

54. Schriefer ME, Sacci JB, Taylor JP, Higgins JA, Azad AF. Murine typhus: updated roles of multiple urban components and a second typhuslike rickettsia. $J$ Med Entomol. 1994;31(5):681-685. doi:10.1093/jmedent/31.5.681

55. Blanton LS, Idowu BM, Tatsch TN, Henderson JM, Bouyer DH, Walker DH. Opossums and cat fleas: new insights in the ecology of murine typhus in Galveston, Texas. Am J Trop Med Hyg. 2016;95(2):457-461. doi:10.4269/ajtmh.16-0197

56. Buttery CM, Magnuson LW, McLerran G, Villarreal T. Endemic (murine) typhus in Corpus Christi. Tex Med. 1984;80(8):53-54.

57. Boostrom A, Beier MS, Macaluso JA, et al. Geographic association of Rickettsia felis-infected opossums with human murine typhus, Texas. Emerg Infect Dis. 2002;8(6):549-554. doi:10.32 01/eid0806.010350

58. Adjemian J, Parks S, McElroy K, et al. Murine typhus in Austin, Texas, USA, 2008. Emerg Infect Dis. 2010;16(3):412-417. doi:10.3201/eid1603.091028

59. Older JJ. The epidemiology of murine typhus in Texas, 1969. JAMA . 1970;214(11):2011-2017. doi:10.1001/jama.1970.03180 110021004

60. Rust MK. The biology and ecology of cat fleas and advancements in their pest management: a review. Insects. 2017;8(4):118. doi:10.3390/insects 8040118

61. Bringham GD. Susceptibility of the opossum (Didelphis virginiana) to the virus of endemic typhus fever. Public Health Rep. 1936;51(13):333-337.

62. Blanton LS, Vohra RF, Fistein L, Quade B, Walker DH, Bouyer DH. Rickettsiae within the fleas of feral cats in Galveston, Texas. Vector Borne Zoonotic Dis. 2019;19 (9):647-651. doi:10.1089/vbz.2018.2402

63. Nogueras MM, Pons I, Ortuno A, et al. Molecular detection of Rickettsia typhi in cats and fleas. PLoS One. 2013;8(8):e71386. doi:10.1371/journal.pone.0071386

64. Irons JV, Bohls SW, Thurman DC, McGregor T. Probable role of the cat flea, Ctenocephalides felis, in transmission of murine typhus. Am J Trop Med. 1944;24(6):359-362. doi:10.4269/ ajtmh.1944.s1-24.359

65. Raynal JH. Le chat dans l'epidemiologie du typhus exanthematique murin. Bull Soc Pathol Exot Filiales. 1947;40(9-10): 367-375.

66. Beck MD, Van Allen A. Typhus fever in California, 1916-1945, inclusive; an epidemiologic and field laboratory study. Am J Hyg. 1947;45(3):335-354

67. Lepine PP, Lorando N. Le typhus exanthematique du chat. Bulletin De La Societe De La Pathologie Exotique Et De Ses Filiales. 1935;28:356-360.

68. Nogueras MM, Pons I, Pla J, et al. The role of dogs in the eco-epidemiology of Rickettsia typhi, etiological agent of Murine typhus. Vet Microbiol. 2013;163(1-2):97-102. doi:10. 1016/j.vetmic.2012.11.043

69. Huxsoll DL, Shirai A, Robinson DM, Yap LF, Lim BL. Presence of antibodies to scrub typhus and murine typhus in dogs from Selangor, Peninsular, Malaysia. Southeast Asian J Trop Med Public Health. 1977;8(2):232-235.

70. Soliman AK, Botros BA, Ksiazek TG, Hoogstraal H, Helmy I, Morrill JC. Seroprevalence of Rickettsia typhi and Rickettsia conorii infection among rodents and dogs in Egypt. J Trop Med Hyg. 1989;92(5):345-349.
71. Lledo L, Gegundez MI, Serrano JL, Saz JV, Beltran M. A sero-epidemiological study of Rickettsia typhi infection in dogs from Soria province, central Spain. Ann Trop Med Parasitol. 2003;97(8):861-864. doi:10.1179/000349803225002679

72. Bacellar F, Dawson JE, Silveira CA, Filipe AR. Antibodies against rickettsiaceae in dogs of Setubal, Portugal. Cent Eur J Public Health. 1995;3(2):100-102.

73. Nanayakkara DM, Rajapakse RP, Wickramasinghe S, Kularatne SA. Serological evidence for exposure of dogs to Rickettsia conorii, Rickettsia typhi, and Orientia tsutsugamushi in Sri Lanka. Vector Borne Zoonotic Dis. 2013;13(8):545-549. doi:10.1089/vbz.2012.1049

74. Martinez-Ortiz D, Torres-Castro M, Koyoc-Cardena E, et al. Molecular evidence of Rickettsia typhi infection in dogs from a rural community in Yucatan, Mexico. Biomedica. 2016;36: 45-50. doi:10.7705/biomedica.v36i2.2913

75. Dzul-Rosado K, Lugo-Caballero C, Tello-Martin R, Lopez-Avila K, Zavala-Castro J. Direct evidence of Rickettsia typhi infection in Rhipicephalus sanguineus ticks and their canine hosts. Open Vet J. 2017;7(2):165-169. doi:10.4314/ovj.v7i2.14

76. Dyer RE, Ceder ET, Workman WG, Rumreich A, Badger LF. Typhus fever: transmission of endemic typhus by rubbing either crushed infected fleas or infected flea feces into wounds. Public Health Rep. 1932;47(3):131-133. doi:10.2307/4580312

77. Adams JR, Schmidtmann ET, Azad AF. Infection of colonized cat fleas, Ctenocephalides felis (Bouche), with a rickettsia-like microorganism. Am J Trop Med Hyg. 1990;43(4):400-409. doi:10.4269/ajtmh.1990.43.400

78. Wedincamp J, Foil LD. Vertical transmission of Rickettsia felis in the cat flea (Ctenocephalides felis Bouche). J Vector Ecol. 2002;27(1):96-101.

79. Eremeeva ME, Capps D, McBride CL, et al. Detection of Rickettsia asembonensis in fleas (Siphonaptera: pulicidae, Ceratophyllidae) collected in five counties in Georgia, United States. J Med Entomol. 2020;57(4):1246-1253. doi:10.1093/jme/ tjaa029

80. Behar A, McCormick LJ, Perlman SJ. Rickettsia felis infection in a common household insect pest, Liposcelis bostrychophila (Psocoptera: liposcelidae). Appl Environ Microbiol. 2010;76 (7):2280-2285. doi:10.1128/AEM.00026-10

81. Thepparit C, Sunyakumthorn P, Guillotte ML, Popov VL, Foil LD, Macaluso KR. Isolation of a rickettsial pathogen from a non-hematophagous arthropod. PLoS One. 2011;6(1):e16396. doi:10.1371/journal.pone.0016396

82. Sashika M, Abe G, Matsumoto K, Inokuma H. Molecular survey of rickettsial agents in feral raccoons (Procyon lotor) in Hokkaido, Japan. Jpn J Infect Dis. 2010;63(5):353-354.

83. Tay ST, Mokhtar AS, Low KC, et al. Identification of rickettsiae from wild rats and cat fleas in Malaysia. Med Vet Entomol. 2014;28(Suppl 1):104-108. doi:10.1111/mve.12075

84. Ng-Nguyen D, Hii SF, Hoang MT, et al. Domestic dogs are mammalian reservoirs for the emerging zoonosis flea-borne spotted fever, caused by. Rickettsia Felis Sci Rep. 2020;10 (1):4151. doi:10.1038/s41598-020-61122-y

85. Hii SF, Kopp SR, Abdad MY, et al. Molecular evidence supports the role of dogs as potential reservoirs for Rickettsia felis. Vector Borne Zoonotic Dis. 2011;11(8):1007-1012. doi:10.1089/vbz.20 10.0270

86. Luce-Fedrow A, Maina AN, Otiang E, et al. Isolation of Candidatus Rickettsia asemboensis from Ctenocephalides fleas. Vector Borne Zoonotic Dis. 2015;15(4):268-277. doi:10.1089/ vbz.2014.1744

87. Jiang J, Maina AN, Knobel DL, et al. Molecular detection of Rickettsia felis and Candidatus Rickettsia asemboensis in fleas from human habitats, Asembo, Kenya. Vector Borne Zoonotic Dis. 2013;13(8):550-558. doi:10.1089/vbz.2012.1123 
88. Bai Y, Osikowicz LM, Kosoy MY, et al. Comparison of zoonotic bacterial agents in fleas collected from small mammals or host-seeking fleas from a Ugandan region where plague is endemic. mSphere. 2017;2(6). doi:10.1128/ mSphere.00402-17

89. Billeter SA, Diniz PPVDP, Jett LA, et al. Detection of Rickettsia species in fleas collected from cats in regions endemic and nonendemic for flea-borne rickettsioses in California. Vector Borne Zoonotic Dis. 2016;16(3):151-156. doi:10.1089/vbz.2015.1869

90. Kocher C, Morrison AC, Leguia M, et al. Rickettsial disease in the Peruvian Amazon Basin. PLoS Negl Trop Dis. 2016;10(7): e0004843. doi:10.1371/journal.pntd.0004843

91. Oteo JA, Portillo A, Portero F, Zavala-Castro J, Venzal JM, Labruna MB. 'Candidatus Rickettsia asemboensis' and Wolbachia spp. in Ctenocephalides felis and Pulex irritans fleas removed from dogs in Ecuador. Parasit Vectors. 2014;7:455.

92. Troyo A, Moreira-Soto RD, Calderon-Arguedas O, et al. Detection of rickettsiae in fleas and ticks from areas of Costa Rica with history of spotted fever group rickettsioses. Ticks Tick Borne Dis. 2016;7(6):1128-1134. doi:10.1016/j.ttbdis.2016.08. 009

93. Faccini-Martinez AA, Ramirez-Hernandez A, Forero-Becerra E, et al. Molecular evidence of different Rickettsia species in Villeta, Colombia. Vector Borne Zoonotic Dis. 2016;16(2):85-87. doi:10.1089/vbz.2015.1841

94. Betancourt-Ruiz P, Martinez-Diaz HC, Gil-Mora J, et al. Candidatus Rickettsia senegalensis in cat fleas (Siphonaptera: pulicidae) collected from dogs and cats in Cauca, Colombia. J Med Entomol. 2020;57(2):382-387. doi:10.1093/jme/tjz177

95. Silva AB, Vizzoni VF, Costa AP, et al. First report of a Rickettsia asembonensis related infecting fleas in Brazil. Acta Trop. 2017;172:44-49. doi:10.1016/j.actatropica.2017.04.004

96. Tay ST, Koh FX, Kho KL, Sitam FT. Rickettsial infections in monkeys, Malaysia. Emerg Infect Dis. 2015;21(3):545-547. doi:10.3201/eid2103.141457

97. Sansyzbayev Y, Nurmakhanov T, Berdibekov A, et al. Survey for rickettsiae within fleas of great gerbils, Almaty Oblast, Kazakhstan. Vector Borne Zoonotic Dis. 2017;17(3):172-178. doi:10.1089/vbz.2016.2049

98. Low VL, Prakash BK, Tan TK, et al. Pathogens in ectoparasites from free-ranging animals: infection with Rickettsia asembonensis in ticks, and a potentially new species of Dipylidium in fleas and lice. Vet Parasitol. 2017;245:102-105. doi:10.1016/j. vetpar.2017.08.015

99. Nguyen VL, Colella V, Greco G, et al. Molecular detection of pathogens in ticks and fleas collected from companion dogs and cats in East and Southeast Asia. Parasit Vectors. 2020;13(1):420. doi:10.1186/s13071-020-04288-8

100. Nguyen HM, Theppannga W, Vongphayloth K, Douangngeun B, Blacksell SD, Robinson MT. Screening of ectoparasites from domesticated dogs for bacterial pathogens in Vientiane, Lao PDR. Zoonoses Public Health. 2020;67(8):862-868. doi:10.11 11/zph.12753

101. Cevidanes A, Di Cataldo S, Vera F, Lillo P, Millan J. Molecular detection of vector-borne pathogens in rural dogs and associated Ctenocephalides felis fleas (Siphonaptera: pulicidae) in Easter Island (Chile). J Med Entomol. 2018;55(6):1659-1663. doi:10.1093/jme/tjy141

102. Nelson K, Maina AN, Brisco A, et al. A 2015 outbreak of flea-borne rickettsiosis in San Gabriel Valley, Los Angeles County, California. PLoS Negl Trop Dis. 2018;12(4):e0006385. doi:10.1371/journal.pntd.0006385

103. Mullins KE, Maina AN, Krueger L, et al. Rickettsial infections among cats and cat fleas in Riverside County, California. Am J Trop Med Hyg. 2018;99(2):291-296. doi:10.4269/ajtmh.170706
104. Hornok S, Baneth G, Grima A, et al. Molecular investigations of cat fleas (Ctenocephalides felis) provide the first evidence of Rickettsia felis in Malta and Candidatus Rickettsia senegalensis in Israel. New Microbes New Infect. 2018;25:3-6. doi:10.1016/j. nmni.2018.05.001

105. Khan SA, Bora T, Chattopadhyay S, Jiang J, Richards AL, Dutta P. Seroepidemiology of rickettsial infections in Northeast India. Trans $R$ Soc Trop Med Hyg. 2016;110(8):487-494. doi: $10.1093 / \operatorname{trstmh} / \operatorname{trw} 052$

106. Kolo AO, Sibeko-Matjila KP, Maina AN, Richards AL, Knobel DL, Matjila PT. Molecular detection of zoonotic rickettsiae and Anaplasma spp. in domestic dogs and their ectoparasites in Bushbuckridge, South Africa. Vector Borne Zoonotic Dis. 2016;16(4):245-252. doi:10.1089/vbz.2015.1849

107. Schriefer ME, Sacci JB, Dumler JS, Bullen MG, Azad AF. Identification of a novel rickettsial infection in a patient diagnosed with murine typhus. J Clin Microbiol. 1994;32(4):949-954. doi:10.1128/JCM.32.4.949-954.1994

108. Parola P. Rickettsia felis: from a rare disease in the USA to a common cause of fever in sub-Saharan Africa. Clin Microbiol Infect. 2011;17 (7):996-1000. doi:10.1111/j.1469-0691.2011.03516.x

109. Socolovschi C, Mediannikov O, Sokhna C, et al. Rickettsia felis-associated uneruptive fever, Senegal. Emerg Infect Dis. 2010;16(7):1140-1142. doi:10.3201/eid1607.100070

110. Richards AL, Jiang J, Omulo S, et al. Human infection with Rickettsia felis, Kenya. Emerg Infect Dis. 2010;16 (7):1081-1086. doi:10.3201/eid1607.091885

111. Sothmann P, Keller C, Krumkamp R, et al. Rickettsia felis infection in febrile children, Ghana. Am J Trop Med Hyg. 2017;96 (4):783-785. doi:10.4269/ajtmh.16-0754

112. Mongkol N, Suputtamongkol Y, Taweethavonsawat P, Foongladda S. Molecular evidence of Rickettsia in human and dog blood in Bangkok. Vector Borne Zoonotic Dis. 2018;18 (6):297-302. doi:10.1089/vbz.2017.2180

113. Chowdhury NF, Paul SK, Aung MS, et al. Nationwide prevalence of Rickettsia felis infections in patients with febrile illness in Bangladesh. New Microbes New Infect. 2017;19:123-125. doi:10.1016/j.nmni.2017.07.005

114. Maina AN, Knobel DL, Jiang J, et al. Rickettsia felis infection in febrile patients, western Kenya, 2007-2010. Emerg Infect Dis. 2012;18(2):328-331. doi:10.3201/eid1802.111372

115. Mourembou G, Lekana-Douki JB, Mediannikov O, et al. Possible role of Rickettsia felis in acute febrile illness among children in Gabon. Emerg Infect Dis. 2015;21(10):1808-1815. doi:10.3201/ eid 2110.141825

116. Mediannikov O, Fenollar F, Bassene H, et al. Description of "yaaf", the vesicular fever caused by acute Rickettsia felis infection in Senegal. J Infect. 2013;66(6):536-540. doi:10.1016/j.jinf.2012.10.005

117. Mediannikov O, Socolovschi C, Million M, et al. Molecular identification of pathogenic bacteria in eschars from acute febrile patients, Senegal. Am J Trop Med Hyg. 2014;91(5):1015-1019. doi:10.4269/ajtmh.13-0629

118. Parola P, Mediannikov O, Dieme C, Raoult D. Reply to Slesak et al.: so much about Rickettsia felis infection to be discovered. Proc Natl Acad Sci U S A. 2015;112(48):E6595-6596. doi:10.1073/pnas.1517919112

119. Dittrich S, Phommasone K, Anantatat T, et al. Rickettsia felis infections and comorbid conditions, Laos, 2003-2011. Emerg Infect Dis. 2014;20(8):1402-1404. doi:10.3201/eid2008.131308

120. Mediannikov O, Abat C, Sokhna C, Raoult D. Parallel decline of malaria and Rickettsia felis infections in Senegal. Am J Trop Med Hyg. 2018;99(2):360-361. doi:10.4269/ajtmh.17-0194

121. Dieme C, Bechah Y, Socolovschi C, et al. Transmission potential of Rickettsia felis infection by Anopheles gambiae mosquitoes. Proc Natl Acad Sci U S A. 2015;112(26):8088-8093. doi:10.1073/ pnas. 1413835112 
122. Billeter SA, Metzger ME. Limited evidence for Rickettsia felis as a cause of zoonotic flea-borne rickettsiosis in Southern California. J Med Entomol. 2017;54(1):4-7. doi:10.1093/jme/tjw179

123. Blanton LS, Walker DH. Flea-borne rickettsioses and rickettsiae. Am J Trop Med Hyg. 2017;96(1):53-56. doi:10.4269/ajtmh.160537

124. Labruna MB, Walker DH. Rickettsia felis and changing paradigms about pathogenic rickettsiae. Emerg Infect Dis. 2014;20 (10):1768-1769. doi:10.3201/eid2010.131797

125. Tsioutis C, Zafeiri M, Avramopoulos A, Prousali E, Miligkos M, Karageorgos SA. Clinical and laboratory characteristics, epidemiology, and outcomes of murine typhus: a systematic review. Acta Trop. 2017;166:16-24. doi:10.1016/j.actatropica.2016.10.018

126. Stuart BM, Pullen RL. Endemic (murine) typhus fever: clinical observations of 180 cases. Ann Intern Med. 1945;23:17.

127. Miller ES, Beeson PB. Murine typhus fever. Medicine. 1946;25:1-15. doi:10.1097/00005792-194602000-00001

128. Fergie JE, Purcell K, Wanat D. Murine typhus in South Texas children. Pediatr Infect Dis J. 2000;19(6):535-538. doi:10.1097/ 00006454-200006000-00009

129. Dumler JS, Taylor JP, Walker DH. Clinical and laboratory features of murine typhus in South Texas, 1980 through 1987. JAMA. 1991;266 (10):1365-1370. doi:10.1001/jama.1991.03470100057033

130. Blanton LS, Lea AS, Kelly BC, Walker DH. An unusual cutaneous manifestation in a patient with murine typhus. Am J Trop Med Hyg. 2015;93(6):1164-1167. doi:10.4269/ajtmh.15-0380

131. Blanton LS, Berman MA, Afrouzian M. Case report: renal failure due to focal segmental glomerulosclerosis in a patient with murine typhus. Am J Trop Med Hyg. 2020;103(3):1017-1019. doi:10.4269/ajtmh.20-0116

132. Afzal Z, Kallumadanda S, Wang F, Hemmige V, Musher D. Acute febrile illness and complications due to murine typhus, Texas, USA1,2. Emerg Infect Dis. 2017;23(8):1268-1273. doi:10.3201/ eid2308.161861

133. Silpapojakul K, Ukkachoke C, Krisanapan S, Silpapojakul K. Rickettsial meningitis and encephalitis. Arch Intern Med. 1991;151(9):1753-1757. doi:10.1001/archinte.1991.00400090051 010

134. Rauch J, Eisermann P, Noack B, et al. Typhus group rickettsiosis, Germany, 2010-2017(1). Emerg Infect Dis. 2018;24(7): 1213-1220. doi:10.3201/eid2407.180093

135. van der Vaart TW, van Thiel PP, Juffermans NP, et al. Severe murine typhus with pulmonary system involvement. Emerg Infect Dis. 2014;20(8):1375-1377. doi:10.3201/eid2008.131421

136. Shaked Y, Shpilberg O, Samra Y. Involvement of the kidneys in Mediterranean spotted fever and murine typhus. $Q \mathrm{~J} \mathrm{Med}$. 1994;87(2):103-107.

137. Doppler JF, Newton PN. A systematic review of the untreated mortality of murine typhus. PLoS Negl Trop Dis. 2020;14(9): e0008641. doi:10.1371/journal.pntd.0008641

138. Mawuntu AHP, Johar E, Anggraeni R, et al. Rickettsia felis identified in two fatal cases of acute meningoencephalitis. PLoS Negl Trop Dis. 2020;14(2):e0007893. doi:10.1371/journal.pntd.00 07893

139. Biggs HM, Behravesh CB, Bradley KK, et al. Diagnosis and management of tickborne rickettsial diseases: rocky Mountain spotted fever and other spotted fever group rickettsioses, ehrlichioses, and anaplasmosis - United States. MMWR Recomm Rep. 2016;65(2):1-44. doi:10.15585/mmwr.rr6502a1

140. Patel HM. Murine typhus mistaken for COVID-19 in a young man. BMJ Case Rep. 2020;13:11. doi:10.1136/bcr-2020-239471

141. Phetsouvanh R, Thojaikong T, Phoumin P, et al. Inter- and intra-operator variability in the reading of indirect immunofluorescence assays for the serological diagnosis of scrub typhus and murine typhus. Am J Trop Med Hyg. 2013;88(5):932-936. doi:10.4269/ajtmh.12-0325
142. Lokida D, Sudarmono P, Kosasih H, et al. Comparison of commercial enzyme-linked immunosorbent assay and immunofluorescence assay for diagnosis of acute Rickettsia typhi infections. Vector Borne Zoonotic Dis. 2020;20(2):93-99. doi:10.1089/ vbz.2019.2451

143. Hechemy KE, Stevens RW, Sasowski S, Michaelson EE, Casper EA, Philip RN. Discrepancies in Weil-Felix and microimmunofluorescence test results for Rocky Mountain spotted fever. J Clin Microbiol. 1979;9(2):292-293.

144. La Scola B, Rydkina L, Ndihokubwayo JB, Vene S, Raoult D. Serological differentiation of murine typhus and epidemic typhus using cross-adsorption and Western blotting. Clin Diagn Lab Immunol. 2000;7(4):612-616. doi:10.1128/CDLI.7.4.612-616.2 000

145. Fang R, Raoult D. Antigenic classification of Rickettsia felis by using monoclonal and polyclonal antibodies. Clin Diagn Lab Immunol. 2003;10(2):221-228. doi:10.1128/CDLI.10.2.221228.2003

146. Whiteford SF, Taylor JP, Dumler JS. Clinical, laboratory, and epidemiologic features of murine typhus in 97 Texas children. Arch Pediatr Adolesc Med. 2001;155(3):396-400. doi:10.1001/ archpedi.155.3.396

147. Phakhounthong K, Mukaka M, Dittrich S, et al. The temporal dynamics of humoral immunity to Rickettsia typhi infection in murine typhus patients. Clin Microbiol Infect. 2020;26(6):781-e9. doi:10.1016/j.cmi.2019.10.022

148. Dhawan S, Robinson MT, Stenos J, et al. Selection of diagnostic cutoffs for murine typhus $\operatorname{IgM}$ and $\operatorname{IgG}$ immunofluorescence assay: a systematic review. Am J Trop Med Hyg. 2020;103 (1):55-63. doi:10.4269/ajtmh.19-0818

149. Blanton LS, Walker DH, Bouyer DH, et al. Rickettsia and Orientia. In: Carroll KC, Pfaller MA, Landry ML, editors. Manual of Clinical Microbiology. Vol. 1. 12th. Washington, DC: ASM Press; 2019:1149-1162.

150. Paris DH, Dumler JS. State of the art of diagnosis of rickettsial diseases: the use of blood specimens for diagnosis of scrub typhus, spotted fever group rickettsiosis, and murine typhus. Curr Opin Infect Dis. 2016;29(5):433-439. doi:10.1097/ QCO.0000000000000298

151. Stafford IA, Centeno FH, Al Mohajer M, et al. Successful detection of unrecognized Rickettsia typhi in pregnancy using cell-free next-generation sequencing. Case Rep Obstet Gynecol. 2020;2020:6767351. doi:10.1155/2020/6767351

152. Kissenkotter J, Hansen S, Bohlken-Fascher S, et al. Development of a pan-rickettsial molecular diagnostic test based on recombinase polymerase amplification assay. Anal Biochem. 2018;544:29-33. doi:10.1016/j.ab.2017.12.018

153. Walker DH, Burday MS, Folds JD. Laboratory diagnosis of Rocky Mountain spotted fever. South Med J. 1980;73(11):14431446, 1449. doi:10.1097/00007611-198011000-00007

154. Elliott I, Batty EM, Ming D, et al. Oxford Nanopore MinION sequencing enables rapid whole genome assembly of Rickettsia typhi in a resource-limited setting. Am J Trop Med Hyg. 2020;102 (2):408-414. doi:10.4269/ajtmh.19-0383

155. Howard A, Fergie J. Murine typhus in South Texas children: an 18-year review. Pediatr Infect Dis J. 2018;37(11):1071-1076. doi:10.1097/INF.0000000000001954

156. Rolain JM, Maurin M, Vestris G, Raoult D. In vitro susceptibilities of 27 rickettsiae to 13 antimicrobials. Antimicrob Agents Chemother. 1998;42(7):1537-1541. doi:10.1128/AAC. 42.7.1537

157. Rolain JM, Stuhl L, Maurin M, Raoult D. Evaluation of antibiotic susceptibilities of three rickettsial species including Rickettsia felis by a quantitative PCR DNA assay. Antimicrob Agents Chemother. 2002;46(9):2747-2751. doi:10.1128/AAC.46.9.27472751.2002 
158. Dumler JS. Clincial disease: current treatment and new challenges. In: Palmer $\mathrm{GH}$, Azad AF, editors. Intracellular Pathogens II: Rickettsiales. Washington, DC: ASM Press; 2012:1-39.

159. Newton PN, Keolouangkhot V, Lee SJ, et al. A prospective, open-label, randomized trial of doxycycline versus azithromycin for the treatment of uncomplicated murine typhus. Clin Infect Dis. 2019;68(5):738-747. doi:10.1093/cid/ciy563

160. Moffa M, Brook I. Tetracyclines, glycyclines, and chloramphenicol. In: Bennett JE, Dolin R, Blaser MJ. editors. Mandell, Douglas, and Bennett's Principles and Practice of Infectious Diseases. Vol. 1. 9th. Philidelphia: Elsevier; 2020:318-336.

161. Blanton LS, Wilson NM, Quade BR, Walker DH. Susceptibility of Rickettsia rickettsii to tigecycline in a cell culture assay and animal model for Rocky Mountain spotted fever. Am J Trop Med Hyg. 2019;101(5):1091-1095. doi:10.4269/ajtmh.19-0445

162. Fernando SL, Hudson BJ. Rapid desensitization to doxycycline. Ann Allergy Asthma Immunol. 2013;111(1):73-74. doi:10.1016/j. anai.2013.05.005

163. Stollings JL, Chadha SN, Paul AM, Shaver CM, Hagaman D. Doxycycline desensitization for a suspected case of ehrlichiosis. J Allergy Clin Immunol Pract. 2014;2(1):103-104. doi:10.1016/j. jaip.2013.08.002

164. Mahara F. Japanese spotted fever: report of 31 cases and review of the literature. Emerg Infect Dis. 1997;3(2):105-111. doi:10.3201/eid0302.970203

165. Gikas A, Doukakis S, Pediaditis J, Kastanakis S, Manios A, Tselentis Y. Comparison of the effectiveness of five different antibiotic regimens on infection with Rickettsia typhi: therapeutic data from 87 cases. Am J Trop Med Hyg. 2004;70(5):576-579. doi:10.4269/ajtmh.2004.70.576

166. Holman RC, Paddock CD, Curns AT, Krebs JW, McQuiston JH, Childs JE. Analysis of risk factors for fatal Rocky Mountain spotted fever: evidence for superiority of tetracyclines for therapy. J Infect Dis. 2001;184(11):1437-1444. doi:10.1086/ 324372

167. Botelho-Nevers E, Edouard S, Leroy Q, Raoult D. Deleterious effect of ciprofloxacin on Rickettsia conorii-infected cells is linked to toxin-antitoxin module up-regulation. $J$ Antimicrob Chemother. 2012;67(7):1677-1682. doi:10.1093/jac/dks089

168. Botelho-Nevers E, Rovery C, Richet H, Raoult D. Analysis of risk factors for malignant Mediterranean spotted fever indicates that fluoroquinolone treatment has a deleterious effect. J Antimicrob Chemother. 2011;66(8):1821-1830. doi:10.1093/ $\mathrm{jac} / \mathrm{dkr} 218$
169. Keysary A, Itzhaki A, Rubinstein E, Oron C, Keren G. The in-vitro anti-rickettsial activity of macrolides. $J$ Antimicrob Chemother. 1996;38(4):727-731. doi:10.1093/jac/38.4.727

170. Ruiz Beltran R, Herrero Herrero JI. Deleterious effect of trimethoprim-sulfamethoxazole in Mediterranean spotted fever. Antimicrob Agents Chemother. 1992;36(6):1342-1343. doi:10. 1128/AAC.36.6.1342

171. Cohlan SQ. Teratogenic Agents and Congenital Malformations. $J$ Pediatr. 1963;63:650-659. doi:10.1016/S0022-3476(63) 80375-3

172. Cohlan SQ. Tetracycline staining of teeth. Teratology. 1977;15 (1):127-129. doi:10.1002/tera.1420150117

173. Herbert WN, Seeds JW, Koontz WL, Cefalo RC. Rocky Mountain spotted fever in pregnancy: differential diagnosis and treatment. South Med J. 1982;75(9):1063-1066. doi:10.1097/ 00007611-198209000-00008

174. Cross R, Ling C, Day NP, McGready R, Paris DH. Revisiting doxycycline in pregnancy and early childhood-time to rebuild its reputation? Expert Opin Drug Saf. 2016;15(3):367-382. doi:10.1517/14740338.2016.1133584

175. McGready R, Prakash JA, Benjamin SJ, et al. Pregnancy outcome in relation to treatment of murine typhus and scrub typhus infection: a fever cohort and a case series analysis. PLoS Negl Trop Dis. 2014;8(11):e3327. doi:10.1371/journal.pntd.0003327

176. Kimberil DW, Brady MT, Jackson MA, Long SS. demic typhus (murine typhus). In: Red Book 2018: Report of the Committee on Infectious Diseases. 31st ed. Elk Grove Village, IL: American Academy of Pediatrics; 2018:864-865.

177. Grossman ER, Walchek A, Freedman H. Tetracyclines and permanent teeth: the relation between dose and tooth color. Pediatrics. 1971;47(3):567-570.

178. Todd SR, Dahlgren FS, Traeger MS, et al. No visible dental staining in children treated with doxycycline for suspected Rocky Mountain spotted fever. $J$ Pediatr. 2015;166 (5):1246-1251. doi:10.1016/j.jpeds.2015.02.015

179. Hernandez Cabrera M, Angel-Moreno A, Santana E, et al. Murine typhus with renal involvement in Canary Islands, Spain. Emerg Infect Dis. 2004;10(4):740-743. doi:10.3201/eid1004.030532

180. Pratt HD. The changing picture of murine typhus in the United States. Ann N Y Acad Sci. 1958;70(3):516-527. doi:10.1111/ j.1749-6632.1958.tb35408.x

181. Mohr CO, Morlan HB. The nature of parasitism of the opossum by fleas in southwestern Georgia. $J$ Parasitol. 1959;45 (2):233-237. doi:10.2307/3286539

\section{Publish your work in this journal}

Research and Reports in Tropical Medicine is an international, peerreviewed, open access journal publishing original research, case reports, editorials, reviews and commentaries on all areas of tropical medicine, including: Diseases and medicine in tropical regions; Entomology; Epidemiology; Health economics issues; Infectious disease; Laboratory science and new technology in tropical medicine;
Parasitology; Public health medicine/health care policy in tropical regions; and Microbiology. The manuscript management system is completely online and includes a very quick and fair peer-review system. Visit http://www.dovepress.com/testimonials.php to read real quotes from published authors. 